\title{
Denis Thériault, Le facteur émotif, Montréal
}

\section{Simona Rossi}

\section{(2) OpenEdition}

\section{Journals}

\section{Edizione digitale}

URL: http://journals.openedition.org/studifrancesi/9705

DOI: 10.4000/studifrancesi.9705

ISSN: 2427-5856

\section{Editore}

Rosenberg \& Sellier

\section{Edizione cartacea}

Data di pubblicazione: 1 décembre 2007

Paginazione: 705

ISSN: 0039-2944

\section{Notizia bibliografica digitale}

Simona Rossi, «Denis Thériault, Le facteur émotif, Montréal», Studi Francesi [Online], 153 (LI | III) | 2007, online dal 30 novembre 2015, consultato il 11 janvier 2021. URL: http://journals.openedition.org/ studifrancesi/9705 ; DOI: https://doi.org/10.4000/studifrancesi.9705

Questo documento è stato generato automaticamente il 11 janvier 2021.

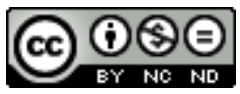

Studi Francesi è distribuita con Licenza Creative Commons Attribuzione - Non commerciale - Non opere derivate 4.0 Internazionale. 


\title{
Denis Thériault, Le facteur émotif, Montréal
}

\author{
Simona Rossi
}

\section{NOTIZIA}

DENIS THÉRIAULT, Le facteur émotif, Montréal, XYZ Éditeur, 2005, pp. 118.

1 Cosa accade a un postino curioso che prima di consegnare le lettere che trasporta le apre col machiavellico aiuto di un soffio di vapore e trascorre le serate a leggerle avidamente? Yves Thériault mette in scena un'assurda vicenda di solitudine moderna, in cui colui che non è in grado di crearsi una vita propria tenta disperatamente di appropriarsi di quella degli altri. Bilodo, un omino inquieto e ossessivo, vive con Bill, il suo pesce rosso, al nono piano di un grattacielo che gioca con le nuvole. Non ha amici, non ha una fidanzata, è orfano di qualsiasi contatto umano e ha molta sete. Di storie, di vita vissuta. È così che si è inventato un nuovo mestiere: il postino-ruba-storie. Ma Bilodo non si limita a leggere le lettere degli abitanti del suo quartiere, violando la loro intimità, le fa sue, le fotocopia, le conserva meticolosamente, le dispone in zelante ordine alfabetico in uno scaffale, s'immagina le risposte. Le sue serate, così, acquistano spessore, i personaggi cartacei di cui farcisce i suoi pensieri e i suoi momenti quotidiani gli regalano una famiglia virtuale e Bilodo non si sente più solo, il vuoto che di notte gli bucava l'anima non c'è più. È sparito, risucchiato dalla girandola vanitosa di eventi e sensazioni della vita altrui. Poi il cambiamento: un giorno nel sacco delle lettere Bilodo ne scorge una nuova, quella di Ségolène, che dalla Guadalupa scrive a Gaston Grandpré. Non si tratta di una lettera come tutte le altre, però, perché contiene solo pochi versi che sembrano un messaggio cifrato. Incuriosito, Bilodo segue con trepidazione crescente l'evolversi della vicenda e si dedica a ricerche approfondite, scoprendo che i versi di Ségolène non sono altro che degli haikus, i poemi classici giapponesi. Intanto i giorni si susseguono rapidamente, i versi si fanno sempre più languidi e a poco a poco il cuore di Bilodo comincia a palpitare d'amore per Ségolène. La lettura delle poesie di quest'ultima diventa la sua unica ragione di vita e la sera, immerso nei suoi scritti 
profumati alla luce di una lampada giallo oro, Bilodo sogna e sospira, immagina la pelle ambrata della donna e i suoi capelli corvini, desidera ardentemente stringerla tra le braccia e immergersi con lei nel mare cristallino dei Caraibi. L'idillio, però, si sa, non può durare, e una tiepida mattina d'autunno Bilodo si trova nel posto sbagliato - o piuttosto giusto? - al momento sbagliato. Vede infatti un Gaston Grandpré piuttosto trafelato correre fuori casa senza notare il pericoloso sopraggiungere di un'auto di grossa cilindrata. Grandpré muore investito sotto gli occhi increduli di Bilodo, che si rende conto immediatamente di come la morte dell'uomo significhi anche l'inevitabile interruzione del suo rapporto d'amore virtuale con Ségolène.

2 Bilodo, allora, si trasforma: da omino insignificante diventa un cavaliere intrepido, il cui obiettivo è uno solo, ossia preservare Ségolène - e lui stesso - dalla sofferenza. Il modo? Sostituirsi a Grandpré. Bilodo affitta l'appartamento dell'uomo a cui ha rubato la storia e la vita, indossa il suo kimono rosso fuoco, trova le copie degli haikus che Grandpré inviava a Ségolène, ne beve avidamente ogni singola sillaba, si lascia trasportare dalla magica atmosfera che regna nella sua nuova casa, zeppa di un'incredibile quantità di ninnoli e libri giapponesi, si esercita per giorni nella scrittura e infine si sente pronto. Col cuore gonfio d'ansia invia la sua prima lettera a Ségolène e attende. La risposta arriva dopo qualche giorno e Bilodo esulta: la sua amica di penna sembra non essersi accorta di nulla e finalmente lui ha una vita vera. Sennonché col tempo il personaggio di Thériault diventa davvero Grandpré, prima nei sogni e poi anche nella realtà, infatti un giorno si guarda allo specchio e scopre che il suo viso si è deformato, assumendo i tratti marcati di Grandpré. A quale destino andrà incontro questo postino-ruba-storie, che ha voluto sovvertire l'ordine delle cose e sfidare il fato? La fine di Grandpré sarà anche la sua? Non possiamo far altro che lasciar parlare la storia. 